\title{
LEARNING TRAJECTORIES WITH BAYESIAN STUDENT MODEL FOR AUTONOMOUS STUDY IN FLIPPED LEARNING
}

\author{
L. Descalço', A.B. do Canto Filho², J. Valdeni de Lima² \\ ${ }^{1}$ Departamento de Matemática, Universidade de Aveiro (PORTUGAL) \\ ${ }^{2}$ CINTED, Universidade Federal do Rio Grande do Sul (BRAZIL)
}

\begin{abstract}
As a complementary tool for learning Calculus, we have been using SIACUA, a computer system designed to help autonomous learning, which is based on the use of parameterized questions with detailed solutions, also parameterized, with a Bayesian user model for feedback. This system has proven to be effective in keeping the students working during the classes' period, as the recent data usage we present in this article shows.

A difficulty in flipped learning is to guarantee that students study before the classes. We address this issue by trying to provide the best possible conditions for this autonomous work to occur. Hence, we propose an expansion of SIACUA, by combining it with the model MOTRAC, a model for creating learning objects and learning trajectories for meaningful learning, based on Meaningful Learning Theory and Cognitive Load Theory, to achieve good guidance, together with the already existing Bayesian feedback, in a flipped learning set, with active learning occurring in the classes.
\end{abstract}

In the proposed learning set we also use an assessment computer system: PmatE. System PmatE is being used from 1989, mainly in the yearly science competitions, that nowadays join in our University, in the three days of the competitions, about ten thousand students, from all ages, from basic to secondary schools.

To achieve some extrinsic motivation, and to further guarantee the students study before the classes, we use system PmatE, which imports contents from SIACUA, for assessment in the end of each class.

Past experiences show two main advantages of using two completely different computer systems, one for learning and another one for assessment are: (i) students are more motivated to use the learning system because they know its contents or similar are going to be used for assessment; (ii) students are not afraid of answering questions in the learning system because they know that the diagnosis on this system is not going to be used for assessment and so it is a useful and safe feedback.

Keywords: Bayesian model, parametrized, trajectories, flipped learning.

\section{INTRODUCTION}

We have been using a computer system, named SIACUA, based on the use of parameterized questions $(\mathrm{PQ})$, with a Bayesian user model to compute the feedback, that presents the course to the student with several progress bars showing the Bayesian beliefs covering all the topics of the course ([1],[2],[3],[4]). System SIACUA has been used in the last four years and many true/false questions and multiply choice questions with feedback are available, from basic school to calculus with several variables.

The main goal is to implement student-centred learning and get closer to most effective one-to-one teaching ([5]) by using an appropriated computer system combined with flipped learning. We start with a course of calculus with several variables (Calculus III) for sciences and engineering were, due to the mixture of students with low and high prior knowledge about mathematics it is appropriate to use adaptive instruction in e-learning and enforce pre-requisites ([6]).

The proposed expansion of SIACUA will include two new kinds of learning objects based on MOTRAC ([7]), a model based on Meaningful Learning Theory ([8]) and the Cognitive Load Theory ([6], [9]). The first kind of MOTRAC learning objects (MLOs) are designed to interact with the student with contents he/she already knows. They consist of an expanding contents page with several multiple-choice steps with a different feedback for each option; we call them MCMLOs. Video lectures are as effective as inperson lectures at conveying basic information ([10], [11], [12]), and we propose the replacement of the in-person lectures about the most basic subjects by learning objects containing short videos. These are the second kind of MOTRAC learning objects (VMLOs). 
Students can start by using the MCMLOs to recall what they already know and is relevant to what they will learn, then use VMLOs for a sort introduction to the subject, then use and mark read the references and finally, the parametrized questions together with the Bayesian model are used for further learning and feedback.

\section{PARAMETRIZED QUESTIONS}

A typical limitation for the effective use of Intelligent Tutoring Systems (ITS) in the learning process is the limited number of available questions in the several topics in study. Fortunately, we do not have this difficulty in the University of Aveiro. We can use the questions from PmatE ([13], [14], [15]), a project initiated in 1989, containing now many hundreds of parameterized questions in several areas of knowledge, presently with 1490 parameterized question generators available for mathematics. Since the parameters are instantiated in runtime by the computer, we have, in fact, many thousands of different questions. An instantiated question from PmatE consists of an initial text followed by four statements about that text, randomly chosen from a set of four or more specified in what we call the Question Generator Model (QGM). Hence, the student can say which of the four statements are true or false, and up to four evidences are supplied to SIACUA.

Another project we have for creating parameterized questions is MEGUA ([16]). It includes a package for Sage ([17]), allowing the user to create multiple choice questions, with detailed answer, and sending them immediately to SIACUA. The number of questions we are using from MEGUA is growing, and we have already 7368 questions generated form 776 different QGMs.

\section{LEARNING AND ASSESSMENT}

The Bayesian student model used to compute the belief about the knowledge of the students based on their answers to the parameterized questions in SIACUA requires a change in the way teachers think about knowledge diagnosis when developing questions. Instead of marks to be added to compute the final mark of the student, the teachers must estimate and provide some parameters together with the question. These parameters are: guess - the probability of guessing the question without knowing the concepts it relates to; slip - the probability of giving a wrong answer knowing all concepts; level - the difficulty level of the question; discr - the discrimination of the question. Parameters in the questions are initially estimated by the teachers and to be updated based on students answers to questions and their final marks in the courses.

The model used in SIACUA is based on ([18]) and is implemented using Genie \& Smile ([19], [20]). This model has been tested with simulated students ([21]) and real students ([22], [23]). A detailed description of the model applied to calculus with several variables can be found in ([4]).

Although SIACUA is designed for learning, questions from SIACUA have been used for assessment in PmatE platform. Some usage from current year 2016/2017 in Calculus III is presented in Figure 1, where the blue bars represent the number of questions seen by students in the week, the red bars represent the wrong answers and the green bars represent the correct answers. From the 396 students in Calculus III, 70\% use the application every week and the weeks with more use correspond to the periods where assessment tests with questions using the same QGMs are available in the PmatE platform. 


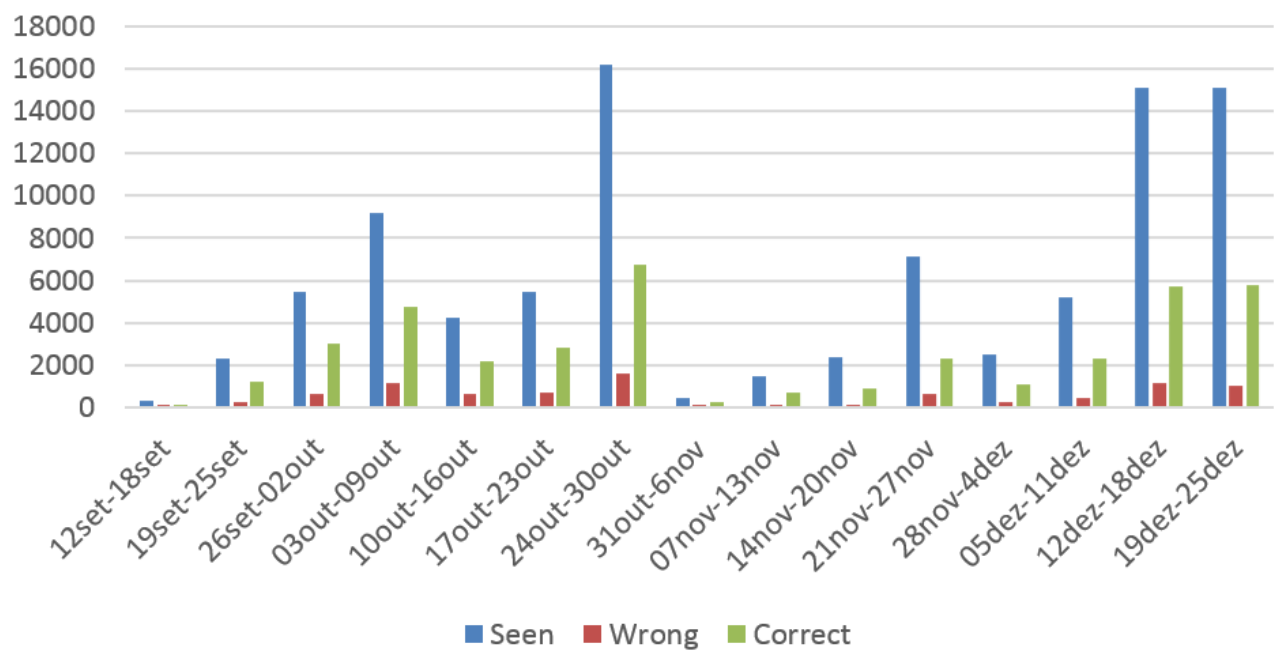

Figure 1: Questions on SIACUA - Calculus III - 2016/2017

The use of SIACUA as a complement to independent study was clearly considered by the students, in several informal surveys, preferential to just having the study material available in MOODLE ([2], [4]).

\section{LEARNING TRAJECTORIES}

In traditional exposition classes, the concepts are presented sequentially to all students. This is known to be ineffective in general since each student learns at a different speed and has a different background. But it is particularly ineffective in calculus since the high number of complex concepts in a single class the teacher presents to accomplish the course program makes it almost impossible for most students to follow the class.

We try to provide conditions for each student to follow his/her natural learning trajectory, instead of being forced to follow the sequence in the class, with the help of a computer system. The classes will then be used to clarify doubts and apply the concepts to solve problems with the help of the teacher and colleagues.

Learning trajectories throughout the several concepts in the course are not determined. Instead, the Bayesian networks are used to trigger suggestions for learning progression. The mechanism is quite simple: after answering a question, if the knowledge of the student in some topics falls below a defined limit, other topics, prerequisites for the topics of the answered question, eventually from previous courses, are suggested for the student to study, who is free to follow the suggestions or not. If the estimated knowledge about a concept gets above another defined limit then learning objects assuming knowledge in that concept become available.

In the following pictures showing learning trajectories we represent concepts by nodes and learning objects by arrows, where dashed arrows represent objects providing knowledge evidence to the system (the parameterized questions). We use the following color coding: green represents a successful path and concept where the student has attained enough knowledge; red represents a path conducing to low knowledge in the destination concept; yellow represents a path conducing to an undefined state were the student's knowledge is not clearly positive or negative; finally, black represents a path that we do not know if was followed by the student and a concept we do not know if has been accessed.

For illustration, we present an example. If we denote by $\mathrm{MLO}_{\mathrm{C}_{1->} \mathrm{C} 2}$ any MLO having only one starting concept $\mathrm{C}_{1}$ and goal concept $\mathrm{C}_{2}$, by $\mathrm{PQ}_{\mathrm{c} 2}$ parameterized questions assessing concept $\mathrm{C}_{2}$, by $\mathrm{MLO}_{\mathrm{c} 2}$ $>\mathrm{C} 3$ any MLO with one starting concept $\mathrm{C}_{2}$ and goal concept $\mathrm{C}_{3}$ and by $\mathrm{PQ}_{c 3}$ parameterized questions assessing concept $\mathrm{C}_{3}$, a typical successful learning trajectory is illustrated by Figure 2 . Assuming the student has shown enough knowledge about concept $C_{1}$ (concept in green color) he/she can use objects $\mathrm{MLO}_{\mathrm{C} 1-\mathrm{C} 2}$ to learn concept $\mathrm{C}_{2}$. After that, the student can provide evidence of knowledge by answering parameterized questions about concept $\mathrm{C}_{2}$. Assuming the student has provided enough evidence of knowledge in concept $\mathrm{C}_{2}$, MLOc2->C3 , the learning objects designed to learn concept $\mathrm{C}_{3}$ starting from concept $\mathrm{C}_{2}$, can be used. The process continues this way with the student alternating 
between learning with MLOs and then learning further and providing knowledge evidence by answering PQs. Although this is the proposed learning trajectory, students are free to proceed any other way since the system is open and many learning objects are always available.

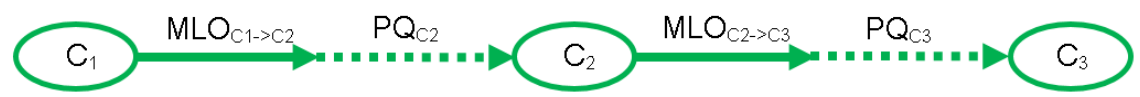

Figure 2: A successful learning trajectory in the concept map

We observe that, by using MLOs with starting concept $C_{1}$ and answering parameterized questions about concept $\mathrm{C}_{2}$, we have two other possibilities in the student learning trajectory. Figure 3 illustrates these possibilities. First possibility (a) is not giving enough knowledge evidence about concept $\mathrm{C}_{2}$. In this case, the student cannot use MLOs designed to learn about concept $\mathrm{C}_{3}$ starting from concept $\mathrm{C}_{2}$ and must proceed by using any of the other available learning objects and questions. Then we have the case (b) of a student that, after using MLOs with starting concept $\mathrm{C}_{1}$ to learn concept $\mathrm{C}_{2}$, gives incorrect answers to questions about $\mathrm{C}_{2}$, meaning he/she did not learn concept $\mathrm{C}_{2}$ as he/she should. In this case, not only MLOs designed to learn $\mathrm{C}_{3}$ from $\mathrm{C}_{2}$ are unavailable but also some suggestions about prerequisite concepts for $\mathrm{C}_{2}$ are presented. The student can follow the suggestions, use other MLOs to learn $\mathrm{C}_{2}$ assuming knowledge on $\mathrm{C}_{1}$ or use available learning objects in other concepts. We note that no dead locks are possible since all parameterized questions and MLOs in the initial concepts of the course are always available, regardless of the student's progress.



(a)

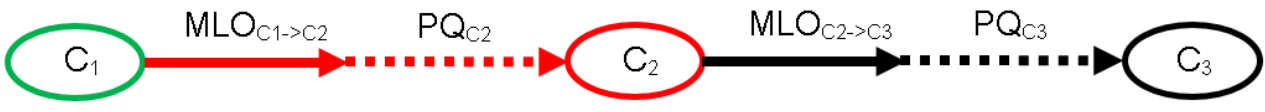

(b)

Figure 3: Other learning trajectory possibilities in the concept map

Hence the learning trajectories of the students are conditioned, although not predetermined.

\section{INVERTED LEARNING}

In the traditional system, classes are used to present the contents of the course including exposition and then application to solve problems. Then the student must study at home and solve further problems applying what they learn in the class. With inverted classrooms, this traditional process is inverted. The students learn by themselves, with the help of materials and references carefully prepared by the teacher. Then in the class they solve further problems together with colleagues with the teacher as adviser, who should provide a flexible learning environment centered on the students.

We propose a model containing a system for the students to use before the class, where the study materials are clearly organized and feedback about the knowledge acquisition is clearly provided. The class must be carefully planned to consider the learning materials supplied. An assessment in the end of each class is required either by a written test or a computer test using the PmatE platform with questions generated from QGM from SIACUA, for a further guarantee that the students will be active during the classes.

\section{CONCLUSIONS}

We have been able to create computer learning systems that are consistently being used by teachers and students and contribute to our main first goal that is to keep the students doing some work during the semester, which improves learning and the final marks in the course.

The proposed model, combining Bayesian networks, a computer science tool particularly appropriate for knowledge estimation and feedback, and a model for specification of learning objects and 
trajectories, defines a learning environment capable of providing real autonomy to students in their preparation for the classes in the flipped classroom model and contributes to our second main goal that is to keep students active in the classes.

\section{ACKNOWLEDGEMENTS}

This work was supported by CIDMA ("Center for Research \& Development in Mathematics and Applications'") and FCT ("FCT- Fundação para a Ciência e a Tecnologia") through project UID/MAT/04106/2013 and grant SFRH/BSAB/114249/2016.

\section{REFERENCES [Arial, 12-point, bold, left alignment]}

[1] L. Descalço and P. Carvalho, "SIACUA - Interactive Computer Learning System, University of Aveiro," http://siacua.web.ua.pt, Accessed 11.05.17.

[2] L. Descalço and P. Carvalho, "Using Parameterized Calculus Questions for Learning and Assessment," Proceedings of $10^{\underline{a}}$ Conferência Ibérica de Sistemas e Tecnologias de Informação, AISTI, pp 710-714, 2015.

[3] L. Descalço, P. Carvalho, J.P. Cruz, P. Oliveira and D. Seabra, "Using Bayesian Networks and Parametrized Questions in Independent Study," EDULEARN15 Proceedings, IATED, pp. 33613368, 2015.

[4] L. Descalço, P. Carvalho, J.P. Cruz, P. Oliveira and D. Seabra, "Computer-assisted independent study in multivariate calculus," EDULEARN15 Proceedings, IATED, pp. 33523360, 2015.

[5] B.S. Bloom, "The 2 sigma problem: The search for methods of group instruction as effective as one-to-one tutoring," Educational researcher, vol. 13, no. 6, pp. 4-16, 1984.

[6] Ruth C. Clark, F. Nguyen and J. Sweller, Efficiency in Learning: Evidence-Based Guidelines to Manage Cognitive Load. Pfeiffer, 2015.

[7] A.B. do Canto Filho, "MOTRAC - Conceptual learning trajectory model," Doctoral dissertation, Universidade Federal do Rio Grande do Sul, Brazil, 2015.

[8] D.P. Ausubel, J.D. Novak and H. Henesian, Educational Psychology: a cognitive view. Holt, Rinehart and Winston, 1978.

[9] F. Paas, A. Renkl and J. Sweller, "Cognitive Load Theory and Instructional Design: Recent Developments," Educational Psychologist, vol. 38, no. 1, pp. 1-4, 2003.

[10] P.A. Cohen, B.J. Ebeling and J.A. Kulik, "A meta-analysis of outcome studies of visual-based instruction," Educational Technology Research and Development, vol. 29, no. 1, pp. 26-36, 1981.

[11] B.J. McNeil, "A Meta-analysis of interactive video instruction: A 10 year review of achievement effects", Doctoral Dissertation, University of Idaho, USA, 1989.

[12] D. Zhang, L. Zhou, R.O. Briggs and J.F. Nunamaker, "Instructional video in e-learning: Assessing the impact of interactive video on learning effectiveness," Information \& Management, vol. 43, no. 1, 15-27, 2006.

[13] PmatE - Mathematics Teaching Project, University of Aveiro, http://pmate.ua.pt, Accessed 11.05.17.

[14] R.O. Isidro, J. Sousa Pinto and B. Anjo, "SA3C - Platform of Evaluation System and Computer Assisted Learning," WEAS Transactions on Advances in Engineering Education, vol. 1, no. 2, pp. 1-6, 2005.

[15] J. Camejo, A. Silva, L. Descalço and P. Oliveira, "ModelMaker, a Multidisciplinary Web Web Application to Build Question Generator Models From Basic to Higher Education," EDULEARN16 Proceedings, IATED, pp. 5095-5103, 2016.

[16] J.P. Cruz, P. Oliveira and D. Seabra, "Exercise templates with Sage," Tbilisi Mathematical Journal, vol. 5, no. 2, pp. 37-44, 2012. 
[17] Sage Mathematics Software, http://www.sagemath.org, Accessed 11.05.17.

[18] E. Millán, "Bayesian system for student modeling," Al Communications, vol. 13, no. 4, pp. 277278, 2000.

[19] M.J. Druzdzel, "SMILE: Structural Modeling, Inference, and Learning Engine and GeNle: A development environment for graphical decision-theoretic models (Intelligent Systems Demonstration)," Proceedings of the Sixteenth National Conference on Artificial Intelligence, AAAI Press/The MIT Press, pp. 902-903, 1999.

[20] Genie and Smile, Bayes Fusion, LLC, https://www.bayesfusion.com/, Accessed 11.05.17.

[21] E. Millán and José-Luis Pérez-de-la-Cruz, "A Bayesian Diagnostic Algorithm for Student Modeling and its Evaluation," User Model. User Modeling and User-Adapted Interaction, vol. 12, no. 2, pp. 281-330, 2002.

[22] G. Castillo, L. Descalço, S. Diogo, E. Millán, P. Oliveira and B. Anjo, "Computerized evaluation and diagnosis of student's knowledge based on Bayesian Networks", Sustaining Tel: From Innovation to Learning and Practice, Lecture Notes in Computer Science, vol. 6383, pp. 494499, 2010.

[23] E. Millán, L. Descalço, G. Castillo, P. Oliveira and S. Diogo, "Using Bayesian networks to improve knowledge assessment," Computers \& Education, vol. 60, no. 1, pp. 436-447, 2013. 